\title{
ANL/ET/CP-103595
}

\section{Critical Heat Flux and Boiling Heat Transfer to Water in a 3-mm-Diameter Horizontal Tube*}

\author{
Wenhua Yu, Martin W. Wambsganss, John R. Hull \\ Energy Technology Division \\ Argonne National Laboratory \\ Argonne, IL \\ David M. France \\ Department of Mechanical Engineering \\ University of Illinois at Chicago \\ Chicago, IL
}

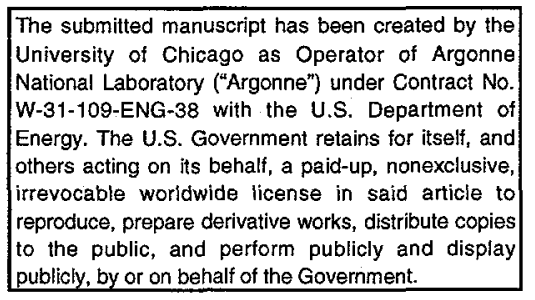

Distribution:

S. Diamond - DOE

H. Drucker

G. R. Fenske - ET

J. R. Hull

R. B. Poeppel - ET

R. E. Price - DOE

J. L. Routbort - ET

R. A. Valentin - ET

M. W. Wambsganss - ET

R. N. Wares - DOE

Th\&EM Section

ET Division File

To be presented at VTMS5 - Vehicle Thermal Management Systems Conference, May 14-17, 2001, Nashville, TN

*Work supported by the U.S. Department of Energy, Office of Heavy Vehicle Technologies and Office of Advanced Automotive Technologies, under Contract W-31-109-Eng-38. 


\section{DISCLAIMER}

This report was prepared as an account of work sponsored by an agency of the United States Government. Neither the United States Government nor any agency thereof, nor any of their employees, make any warranty, express or implied, or assumes any legal liability or responsibility for the accuracy, completeness, or usefulness of any information, apparatus, product, or process disclosed, or represents that its use would not infringe privately owned rights. Reference herein to any specific commercial product, process, or service by trade name, trademark, manufacturer, or otherwise does not necessarily constitute or imply its endorsement, recommendation, or favoring by the United States Government or any agency thereof. The views and opinions of authors expressed herein do not necessarily state or reflect those of the United States Government or any agency thereof. 


\section{DISCLAIMER}

Portions of this document may be illegible in electronic image products. Images are produced from the best available original document. 


\title{
Critical Heat Flux and Boiling Heat Transfer to Water in a 3-mm-Diameter Horizontal Tube
}

\author{
Wenhua Yu, Martin W. Wambsganss, and John R. Hull \\ Energy Technology Division, Argonne National Laboratory \\ David M. France \\ Department of Mechanical Engineering, University of Illinois at Chicago
}

Copyright @ 2001 Society of Automotive Engineers, Inc.

\begin{abstract}
Boiling of the coolant in an engine, by design or by circumstance, is limited by the critical heat flux phenomenon. As a first step in providing relevant engine design information, this study experimentally addressed both rate of boiling heat transfer and conditions at the critical point of water in a horizontal tube of $2.98 \mathrm{~mm}$ inside diameter and $0.9144 \mathrm{~m}$ heated length. Experiments were performed at system pressure of 203 $\mathrm{kPa}$, mass fluxes in range of 50 to $200 \mathrm{~kg} / \mathrm{m}^{2} \mathrm{~s}$, and inlet temperatures in range of ambient to $80^{\circ} \mathrm{C}$. Experimental results and comparisons with predictive correlations are presented.
\end{abstract}

\section{INTRODUCTION}

Trend analyses in the motor vehicle development sector indicate that future engine cooling systems will have to cope with even more heat loads as a result of more powerful engines, more air conditioning, more stringent emissions requirements, and additional auxiliary equipment. Moreover, there is considerable interest in reducing the size of the cooling systems to obtain a better aerodynamic profile. To meet these conditions, it is necessary to design higher-performing cooling systems that occupy less space, are lightweight, and have reduced fluid inventory [1]. Among various new cooling systems proposed by researchers, the nucleate boiling engine cooling system has high potential to meet the challenges [2-5]. An order of magnitude higher heat transfer rates can be achieved in nucleate boiling cooling systems compared to conventional, single-phase, forced-convective cooling systems. However, successful design and application of nucleate boiling cooling systems for engine applications requires that the critical heat flux (CHF) not to be reached. Therefore, a fundamental understanding of flow boiling mechanisms under engine application conditions is required to develop reliable and effective nucleate boiling cooling systems.

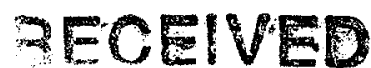

JAN $\cap 52001$
Cooling engine areas such as the head region often involve small metal masses that lead to small coolant channels. This geometry in turn leads to low mass flow rates in order to minimize pressure drop. While considerable research work has been performed to date on boiling heat transfer and CHF phenomenon, results for the conditions necessary for engine cooling systems are limited. It is the purpose of the present study to experimentally investigate the characteristics of coolant boiling and CHF under the conditions of horizontal flow, small channel, and low mass flux. This paper reports the preliminary results of both rates of boiling heat transfer and conditions at the critical point using water as the coolant.

\section{TEST APPARATUS}

The test apparatus used in this investigation was designed and fabricated to study boiling heat transfer and CHF of flowing water, ethylene glycol, and aqueous mixtures of ethylene glycol at high temperature (up to $250^{\circ} \mathrm{C}$ ) and low pressure $(<345 \mathrm{kPa})$. The majority of the piping system was fabricated from 0.25 -in. brass tubing ( 0.03125 in. wall thickness) and Swagelok fittings.

TWO-PHASE LOOP - As shown in figure 1, fluid is pumped through the loop and pressurized by an expansion tank connected to a high-pressure nitrogen bottle. Pressure at the experimental test section is maintained within specifications by adjusting the pressure in the expansion tank.

A rotameter and a turbine-type flowmeter are arranged in a parallel flow configuration in order to measure two ranges of volumetric flow rate. A temperature sensor just upstream from the flowmeters provides for the determination of fluid density and subsequently the mass flow rate of the fluid. Fine adjustment of the fluid flow rate is accomplished with an $A C$ adjustablefrequency drive. 
Exiting the flowmeters, the fluid flows through a system preheater in which the fluid temperature is raised to a desired subcooled temperature for a given test. The preheater consists of a Type 304 stainless steel tube: 4.572- $\mathrm{mm}$ inside diameter, $6.096-\mathrm{mm}$ outside diameter, and $500-\mathrm{mm}$ in length. DC current, at low voltage from a regulated power supply (Sorensen DCR 16-625T) is passed through the preheater tube wall generating resistance heating. The power supply output regulation range is $0.1 \%$ of the voltage or current and has a power capability of up to $10 \mathrm{~kW}$.

Following the preheater, the fluid enters the experimental test section, shown schematically in figure 2. The test section is resistance-heated with DC current by a separate regulated power supply from the preheater (Electronic Measurements Inc. EMHP 40-450-D-111110933) with a maximum output of $18 \mathrm{~kW}$. Voltage drop across the test section is measured directly, and the current is determined from a measurement of the voltage drop across a shunt resistor. Power (heat) input to the test section is calculated as the product of the voltage drop and the current. Immediately following the experimental test section, a pyrex view window provides a view of the flow pattern. Electrical isolation of the preheater/test-section arrangement, for the purpose of eliminating ground loops, is provided by short sections of high-pressure hose, designated ISO (for isolation) in figure 1.

The test section is well insulated thermally from the atmosphere to minimize heat loss to the environment. However, test section heat loss calibration tests were performed, and the small heat loss was subsequently incorporated into the data reduction.

Fluid exits the test section as a two-phase flow and is condensed in the count-current condenser that uses laboratory water as a heat rejection fluid. The condensate leaves the condenser and returns to the pump, closing the system loop.

TEST SECTION - The test section is shown schematically in figure 2. It was fabricated from 2.9845 $\mathrm{mm}$ inside diameter Type 316 stainless steel tubing with a $4.7625-\mathrm{mm}$ outside diameter. The heated length is $0.9144 \mathrm{~m}$.

The bulk fluid temperature is measured at the inlet $\left(T_{i n}\right)$ and outlet $\left(T_{\text {out }}\right)$ of the test section and three intermediate locations $\left(T_{A}, T_{B}, T_{C}\right)$ using sheathed thermocouples places in the fluid stream. (The intermediate measurement locations divide the experimental test section into four segments.) Type $T$ HYP-1 needle temperature probes were selected for these in-stream measurements because they do not significantly affect the flow due to their very small outside diameter of $0.3048 \mathrm{~mm}$. To eliminate the impact of the test section power supply on temperature measurements, the in-stream thermocouples were epoxied in the tube wall isolating them electrically from the tube and the current passing through it.

Figure 2 also illustrates the wall temperature measurement method. The wall temperatures $\left(T_{a}, T_{b}, \cdots, T_{j}\right)$ measured at 10 axial locations over the heated length of the test section with Type $K$ thermocouples. To electrically isolate these thermocouples from the tube, a thin coat of high temperature ceramic epoxy was applied around the circumference of the tube at the measurement points. After oven curing, the thermocouple junctions were coated with the same high-temperature ceramic epoxy and bonded to the thin coating on the tube. This technique allowed the thermocouple junctions to be electrically insulated from the test section tube with current passing through it. All thermocouples, wall and stream, were calibrated prior to installation.

Outlet fluid pressure $\left(p_{o}\right)$ and overall pressure drop $(\Delta p)$ across the test section were measured in all tests. These measurements were incorporated in the data reduction in order to calculate steam temperature distribution along the boiling segment of the test section.

As a safety precaution, the test section was provided with a high-temperature limit interlock. Near the outlet of the test section, the wall temperature $\left(T_{S P}\right)$ is measured and input to a high-temperature limit switch that terminates power to the test section when a preset upper-temperature limit is reached. This interlock protects the test section from overheating due to CHF.

DATA ACQUISITION - A data acquisition system (DAS), consisting of a PC (Compaq) and multiplexor (HewlettPackard, Model 3421A), was assembled to record outputs from all sensors. A data acquisition program was written which includes all calibration equations and conversions to desired engineering units. The data acquisition system provides an on-screen display of analog signals from all sensors and graphs of representative in-stream and wall-temperature measurements. These graphed signals were visually monitored to determine when steady state was achieved. Once that determination was made, all sensoroutput voltages were read 30 times by the DAS and averaged in three sets of 10 data scans each. As a check on steady state, the three data sets were compared for consistency before all of the scans were averaged together for future processing. The final result was a set of measurements, each an average of 30 readings, plus a confirmation of steady state system operation during the collection of data.

Included in the final set of averaged measurements was pertinent information such as input power, mass flux, outlet pressure, pressure drop across the test section, 
and outlet quality. These parameters were also displayed on the DAS screen that allowed the facility operator to set up a particular test.

\section{VALIDATION OF TEST SYSTEM}

To characterize the CHF heat transfer test apparatus, a series of single-phase heat transfer tests were performed.

HEAT LOSS CALIBRATION - While the test section was well insulated to minimize heat loss to the environment, the heat loss was not negligible during the tests because of the low flow rates and large driving temperatures. Heat loss was determined through a special series of experiments in which there was no fluid in the test section. Power was applied to the test section bringing it to a selected temperature. The input power required to maintain the wall temperature at the selected value is the heat loss $q_{e n v}$ corresponding to the driving temperature $\Delta T_{a m b}$, which can be expressed as

$$
q_{e n v}=E I
$$

where $E$ is the voltage drop across the test section, $I$ is the current through the test section, and $\Delta T_{a m b}$ is the temperature different between the test section and ambient.

The heat loss based on these tests is plotted in figure 3 as a function of driving temperature $\Delta T_{a m b}$. It can be seen that the heat loss has a linear function of $\Delta T_{a m b}$ as

$$
q_{e n v}=\alpha \Delta T_{a m b}
$$

where $\alpha$ is a constant dependent on the heat transfer coefficient and the heat transfer surface area between the test section and ambient for this particular test section.

SINGLE-PHASE QUALIFIED TESTS - Single-phase heat transfer tests were performed at system pressure 138 $\mathrm{kPa}$ sufficient to keep the fluid in the liquid phase during heating. A test series was performed in which the flow rates and temperatures were chosen to maintain turbulent flow conditions. The results of the singlephase heat transfer tests for turbulent Reynolds numbers in the range of 4650 to 7700 were in good agreement (all data were $\pm 20 \%$ ) with the PetukhovPopov correlation [6]; see figure 4, in which the local Nusselt numbers are plotted. This result served as verification of the accuracy of the instrumentation, measurements, data acquisition, and data reduction procedures.

\section{BOILING EXPERIMENTAL RESULTS}

TEST PROCEDURE - A series experiments was performed to investigate the characteristics of boiling heat transfer and CHF under the conditions of horizontal flow, small channel, and low mass flux. Tests were performed at a system pressure of $203 \mathrm{kPa}$, mass flux range of 50 to $200 \mathrm{~kg} / \mathrm{m}^{2} \mathrm{~s}$, and inlet temperature range of ambient to $80^{\circ} \mathrm{C}$.

Each CHF measurement resulted from a set of experiments. In these tests, the preheater power supply was set to a certain level to keep the inlet temperature of the test section at a desired point. The test section power supply was increased progressively (in small increments with data recorded at each step) until the critical heat flux was reached.

The local boiling heat transfer coefficient $h(z)$ was calculated as

$$
h(z)=\frac{q^{\prime \prime}}{T_{w}(z)-T_{s a t}(z)}
$$

where the local wall temperature $T_{w}(z)$ was measured directly, the local saturation temperature $T_{\text {sat }}(z)$ was determined based on the two-phase pressure drop and exit saturation temperature measurement, and the heat flux $q^{\prime \prime}$ was calculated from input power and heat loss.

BOILING HEAT TRANSFER COEFFICIENTS - TO present the boiling heat transfer results, the following heat transfer correlations from the literature were selected for comparison with the experimental data: the Chen correlation [7] and the Argonne National Laboratory (ANL) small-channel boiling heat transfer correlation [8].

Comparison with Chen Equation - Chen developed the boiling heat transfer correlation, which is one of the most cited correlations, reasoning that the nucleation transfer mechanism and the convective transfer mechanism are additive. The convective transfer is expressed as a function of the two-phase Reynolds number after Martinelli, and the nucleation transfer is obtained from the nucleate boiling correlation of Forster and Zuber [9]. Figure 5 compares the experimental results of local boiling heat transfer coefficients with the predicted values of the Chen correlation. It can be seen that while the Chen correlation predicts most data reasonably well, the errors of some data are larger than $30 \%$.

Comparison with Modified ANL Equation - Based on the experimental results of boiling heat transfer with two refrigerants, Tran, Wambsganss, and France [8] found that the dominant mechanism to boiling heat transfer in small channels is nucleation. They then correlated boiling heat transfer coefficients as a function of boiling 
number $B_{o}$, liquid Weber number $W e_{l}$, and density ratio $\rho_{l} / \rho_{v}$. Similar trend was observed in the present study. Following the same approach of [8], the experimental data of local boiling heat transfer were correlated as

$$
h=720000\left(B_{o}^{2} W e_{l}\right)^{0.12}\left(\rho_{l} / \rho_{v}\right)^{-0.2}
$$

Figure 6 shows the experimental data and the predicted values obtained with equation (4). The predictions of equation (4) are in good agreement with the present experimental data, and the error scatter is less than that of the Chen correlation predictions.

CHF - The preliminary results of CHF experiments are discussed below.

Boiling Curve - Figure 7 shows the heat flux as a function of wall superheats for the CHF experiments at mass flux $100 \mathrm{~kg} / \mathrm{m}^{2} \mathrm{~s}$ and inlet temperatures in range of ambient to $80^{\circ} \mathrm{C}$. It can be observed that the increase trends of the heat flux with the wall superheats are approximately independent of the inlet temperatures although the inlet temperatures have slight effect on the $\mathrm{CHF}$.

Comparison with Existing Predicative Methods Considerable research work has been performed on the predictive methods for CHF in vertical flow. However predictive methods for CHF in horizontal flow are scarce and inaccurate and no theoretically based predictive procedure is now available in horizontal flow at low mass fluxes. One of the predictive methods proposed by researchers for CHF in horizontal flow is based on the correction to the results of CHF in vertical flow as

$$
C H F_{h o r}=K_{h o r} C H F_{v e r}
$$

Both the Groeneveld-Cheng-Doan method [10] and the Wong-Groeneveld-Cheng method [11] are based on this principle, but the approaches to the correction factor $K_{\text {hor }}$ are different. In Groeneveld-Cheng-Doan method the correction factor $K_{h o r}$ is assumed a linear function of the mass flux while in Wong-Groeneveld-Cheng method the correction factor $K_{\text {hor }}$ is dependent on the flow regime. Figures 8 and 9 compare the experimental CHF with the predicted values of Groeneveld-Cheng-Doan method and Wong-Groeneveld-Cheng method, respectively. It can be seen that the errors of some data are quite large. This suggests that further tests be required to develop appropriate predictive methods for CHF under engine application conditions.

CHF as a Function of Quality - In figure 10, the CHF is plotted as a function of quality. It can be observed that the CHF occurs in the range of high qualities from 0.7 to 1.0. This shows that much higher magnitude of heat can be removed from the engine in nucleate boiling cooling systems than that in conventional forced convective cooling systems because of coolant boiling before the CHF occurs, which verifies preliminarily the feasibility of nucleate boiling cooling systems.

\section{CONCLUSION}

The following conclusions can be drawn from the experimental results of the present study:

1. Based on the experimental data and the ANL smallchannel boiling heat transfer correlation, a new correlation was developed for the prediction of boiling heat transfer coefficients. This correlation has a reasonably low error for the prediction of the local boiling heat transfer coefficients of the present study, and has a less error scatter than that of the Chen correlation.

2. The preliminary results of CHF experiments show that CHF occurs in the range of high qualities from 0.7 to 1.0. This indicates that the nucleate boiling cooling system can remove very high magnitude of heat from the engine because of coolant boiling before the occurrence of $\mathrm{CHF}$.

3. Additional testing is required to investigate predictive methods of CHF under engine application conditions. In particular, tests should be performed in wider test parameter ranges with water as well as with aqueous mixtures of ethylene glycol. These experimental studies are underway at Argonne National Laboratory. A appropriate predictive model may be developed later based on this work.

\section{ACKNOWLEDGMENTS}

This work was supported by the U.S. Department of Energy, Office of Heavy Vehicle Technologies and Office of Advanced Automotive Technologies, under Contract W-31-109-Eng-38. The authors thank Roger K. Smith for his contributions in fabricating the test apparatus, fabricating and instrumenting the test channel, and calibrating the instrumentation.

\section{REFERENCES}

1. M. W. Wambsganss, "Thermal Management in Heavy Vehicles: a Review Identifying Issues and Research Requirements," IMechE Paper No. C543/086.

2. M. Pretscher and N. S. Ap, "Nucleate Boiling Engine Cooling System - Vehicle Study," SAE Paper No. 931132.

3. D. Gentile and S. Zidat, "Influential Parameters in a Boiling Cooling System," Heat and Technology, Vol. 11, No. 1-2,1993.

4. N. A. F. Campbell, D. G. Tilley, S. A. MacGregor, and L. Wong, "Incorporating Nucleate Boiling in a Precision Cooling Strategy for Combustion Engines," SAE Paper No. 971791. 
5. K. Robinson, N. A. F. Campbell, J. G. Hawley, and D. G. Tilley, "A Review of Precision Engine Cooling," SAE Paper No. 1999-01-0578.

6. B. S. Petukhov, "Heat Transfer and Friction in Turbulent Pipe Flow with Variable Physical Properties", Advances in Heat Transfer, Vol. 6, New York: Academic Press, 1970.

7. J. C. Chen, "A Correlation for Boiling Heat Transfer to Saturated Fluids in Convective Flow," Industrial and Engineering Chemistry, Process Design and Development, Vol. 5, No. 3, 1966.

8. T. N. Tran, M. W. Wambsganss, and D. M. France, "Small Circular- and Rectangular-Channel Boiling with Two Refrigerants," International Journal of Multiphase Flow, Vol. 22, No. 3, 1996.

9. H. K. Forster and N. Zuber "Dynamics of Vapor Bubbles and Boiling Heat Transfer," AIChE Journal, Vol. 1, No. 4, 1955.

10. D. C. Groeneveld, S. C. Cheng, and T. Doan, "1986 AECL-UO Critical Heat Flux Lookup Table," Heat Transfer Engineering, Vol. 7, Nos. 1-2, 1986.

11. Y. L. Wong, D. C. Groeneveld, and S. C. Cheng, "CHF Prediction for Horizontal Tubes," International Journal of Multiphase Flow, Vol. 16, No. 1, 1990. 


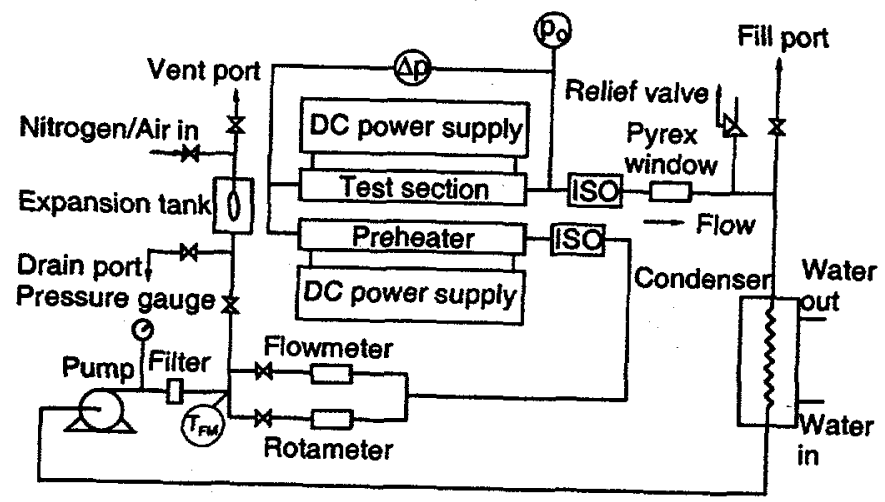

Fig. 1 Schematic of critical heat flux test apparatus 


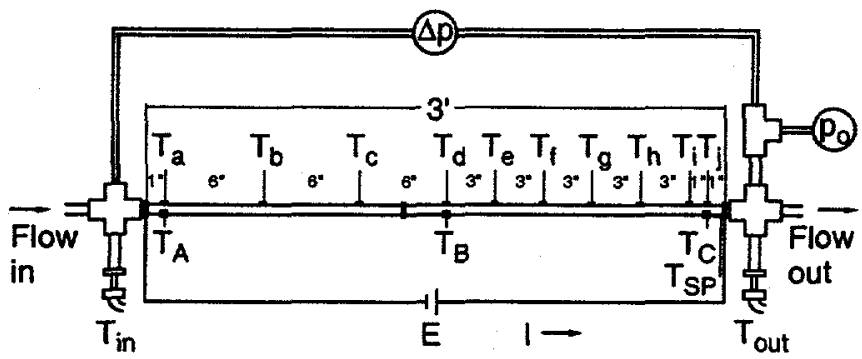

- $T_{A}, T_{B}, T_{C}$ : In-stream coolant temperatures

- $T_{a}, T_{b}, \ldots, T_{j}$ : Tube wall temperatures

- Tsp: Temperature interlock

- $T_{\text {in: }}$ Inlet temperature

- $T_{\text {out: }}$ Outlet temperature

- $p_{0}$ : Outlet pressure

- $\Delta \mathrm{p}$ : Pressure drop across test section

- E: Voltage drop across test section

- I: Current through test section

Fig. 2 Schematic of test section 


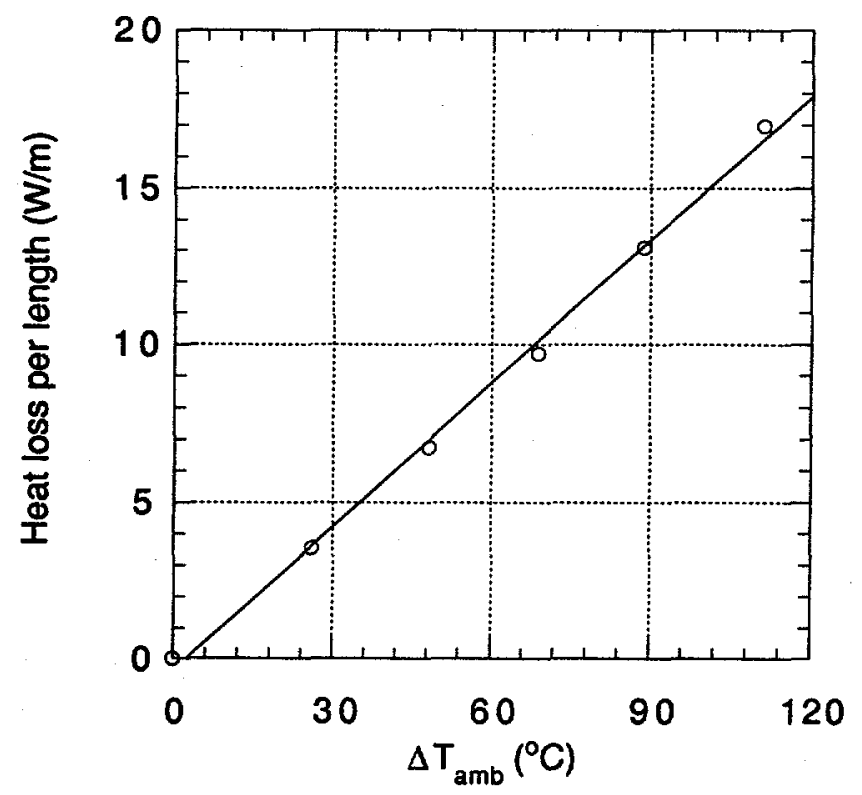

Fig.3 Heat loss calibration 


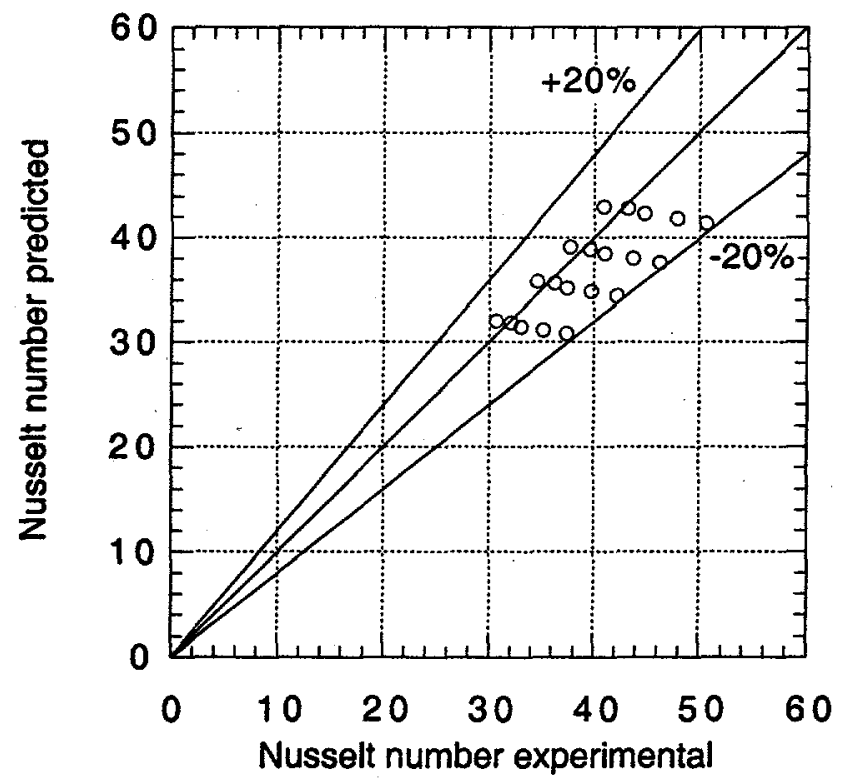

Fig.4 Nusselt number predictions of Petukhov-Popov equation 


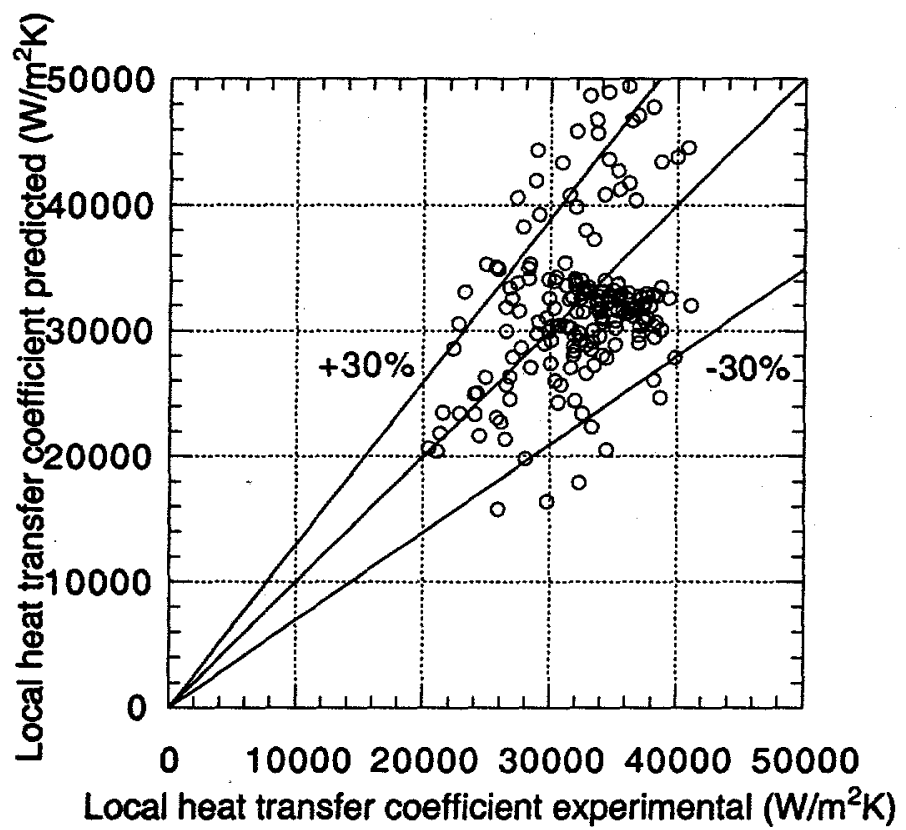

Fig. 5 Local heat transfer coefficient predictions of Chen equation 


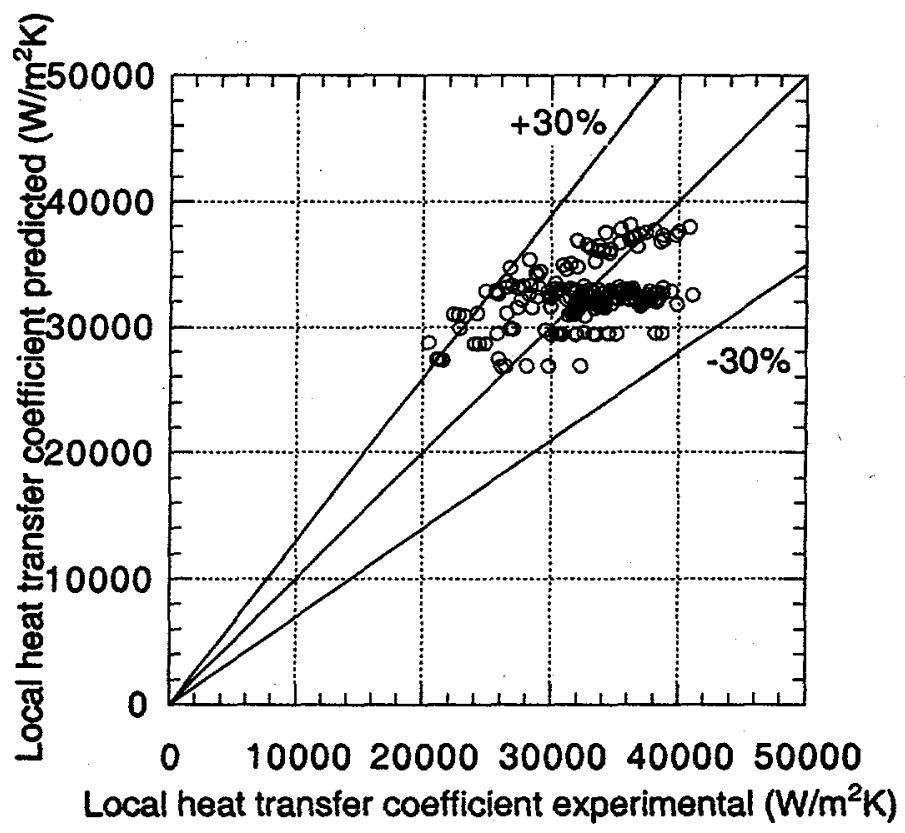

Fig. 6 Local heat transfer coefficient predictions of Modified ANL equation 


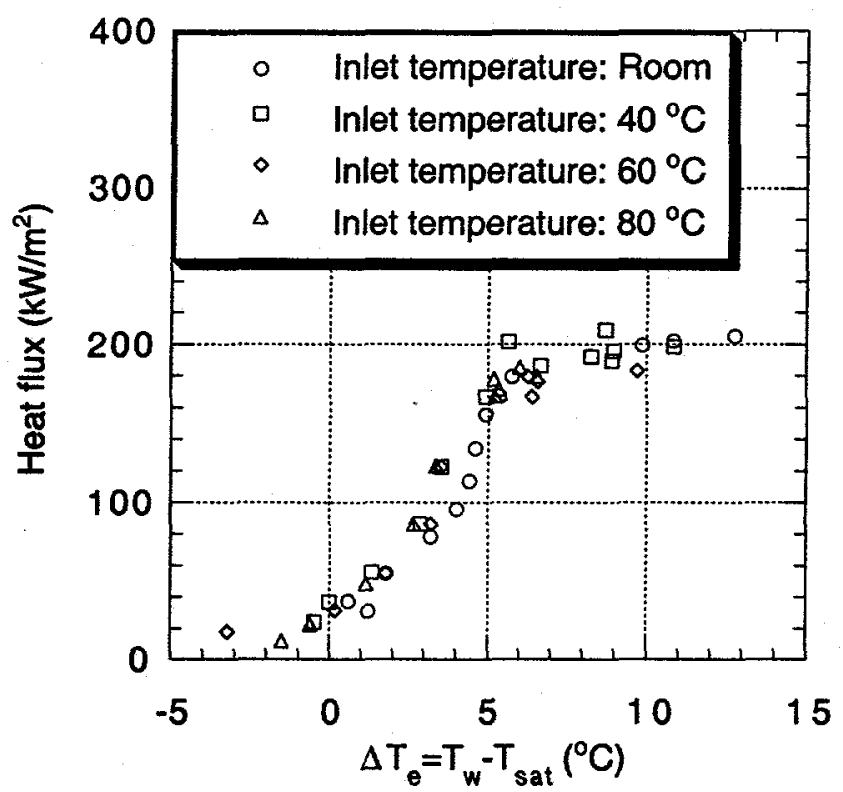

Fig. 7 Boiling curve 


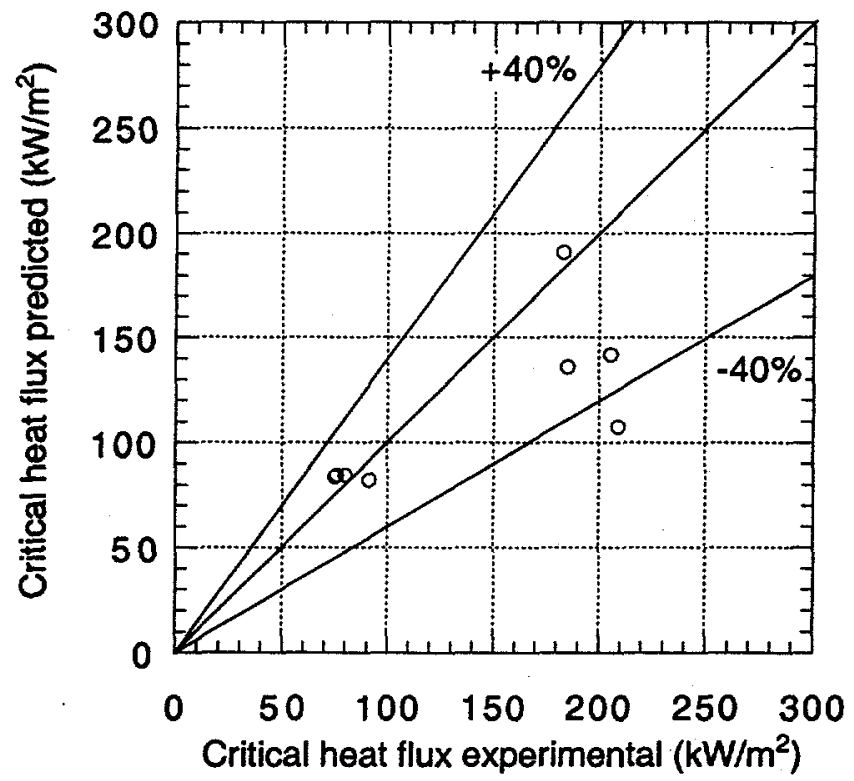

Fig. 8 Critical heat flux predictions of Groeneveld-Cheng-Doan method 


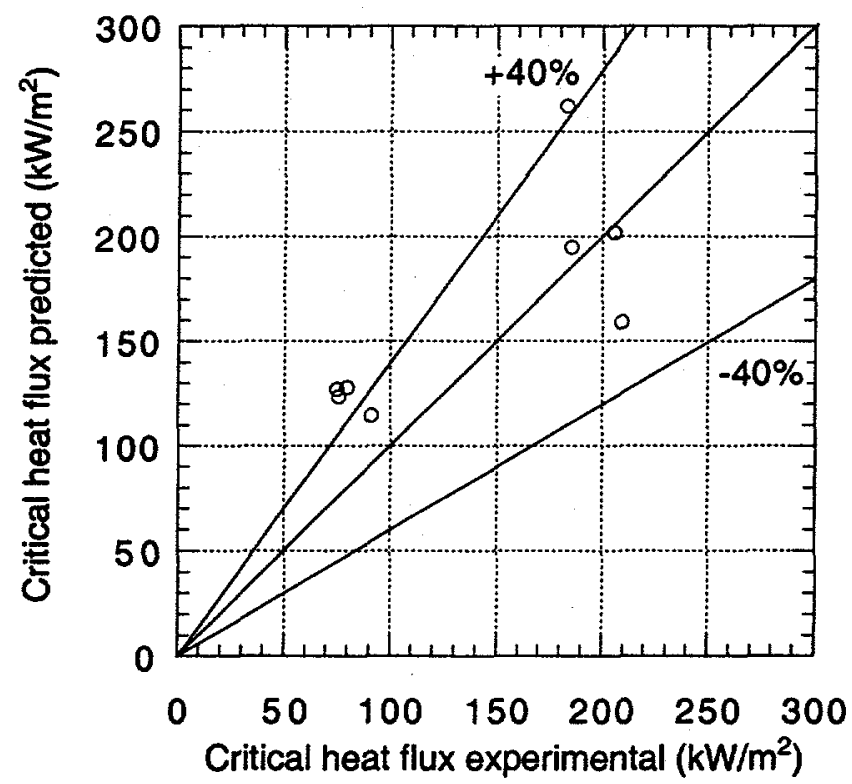

Fig. 9 Critical heat flux predictions of Wong-Groeneveld-Cheng method 


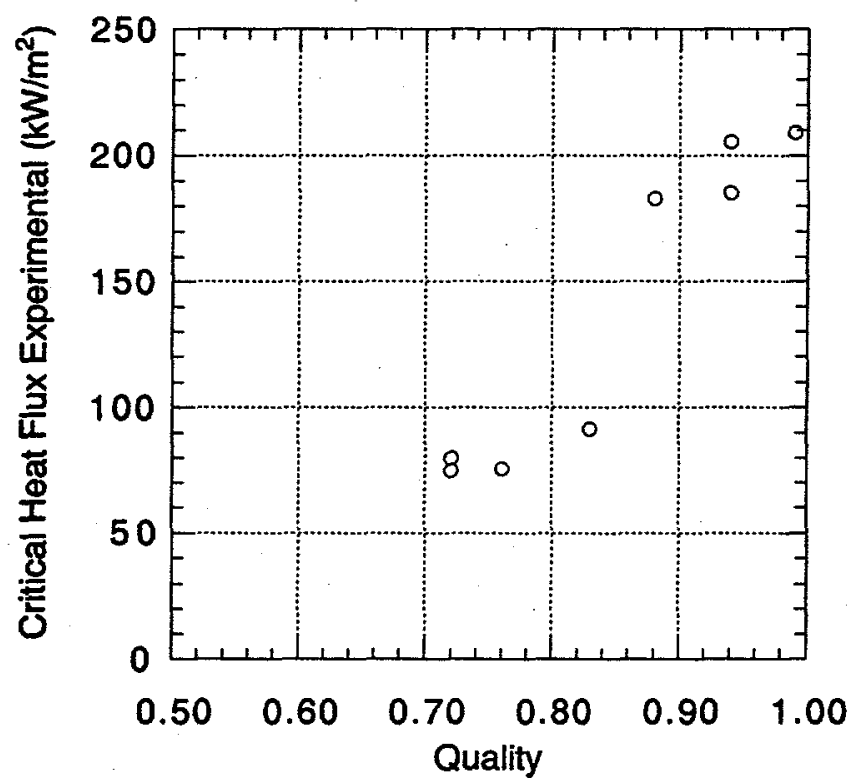

Fig. $10 \mathrm{CHF}$ as a function of quality 